\title{
A Study on the Ecology of the College Listening-and-Speaking Classroom
}

\author{
Ting CHEN
}

Foreign Language College, Huazhong Agricultural University, Wuhan 430070, Hubei, China

tinachen2000@163.com

Keywords: Ecology of education, Classroom, Listening-and-speaking.

\begin{abstract}
This paper analyzes the constructional and functional unbalance in the college listening-and-speaking classroom and proposes the model of mutualism and competition and the model of bionics to maintain the ecological balance in the classroom so as to promote the teaching-and-learning quality.
\end{abstract}

\section{Introduction}

The ecology of education is the research on the interaction between education and its ecological (including natural, social, ethical, psychological and physiological) surroundings. The core is to keep the ecological balance of education. Researchers who describe their research as "ecological" generally share two interests. One is a concern for the environment, the relation of the environment to humans, and the impact humans have on environmental health and sustainability. A second commonality stems from the belief that the phenomenon of interest needs to be understood in context; that is, in relation to other actors, events, practices, and policies within the local and global settings where it occurs. [1]

The ecological research of classroom is focused on the search for understanding human knowing, learning, and action in the setting of classroom. The classroom is not a place for disembodied knowledge, but requires a holistic engagement--a grounded knowing that takes emotions, physical presence, and intellect as a contentious unity [2]. The classroom is seen as a place not only to foster a critical thinking, but also to create a space to fulfill one's commitments to the engagement. The classroom is an important platform for the ecology of education.

Listening and speaking are two important skills in English learning, and the cultivation of the learners' capacity of the two skills has been attached greater and greater importance nowadays. Therefore, measures which reinforce or modify the ecology of the college listening-and-speaking classroom will have important constraining and enabling effects on the teaching-and-learning achievement.

\section{Unbalance Factors of the Ecology of the College Listening-and-Speaking Classroom}

From the perspective of ecology, effective classroom teaching is the ecological interactive process of teacher, student and classroom environment. Teacher and student are the subjects in the ecology of classroom. The dynamic balance of the ecology of classroom can be achieved by the reliance and interaction among teacher, student and classroom environment. However, the dynamic balance is relative. With the development of time, the ecological unbalance has arisen in the college listening-and-speaking classroom. The unbalance factors can be listed as the following:

\section{Constructional Unbalance}

The usual constructional unbalance in the college listening-and-speaking classroom is mainly embodied in the following two aspects. First, the unbalance between the ecological subjects in the classroom, that is, the unbalance between the teaching from the teachers and the learning from the students. In the college listening-and-speaking class, the conventional teaching approach is still 
playing the dominant role. Teachers are the center of the class, while students are only the listeners, recorders and vessels of knowledge. The teacher's dominant status in the classroom has become the barrier to the student's personalized participation and explorative self-construction. The unbalance between the teaching and the learning leads to the lack of vigor and vitality in the college listening-and-speaking classroom. Second, the unbalance between the ecological subjects and the environment of the classroom. According to the law of tolerance and the principle of moderation in the ecology of education, effective teaching and learning can be achieved when all the ecological factors are in their appropriate range. The best size of a language class is 10 to 20 . But with the expansion of higher education in China, the actual size of a college listening-and-speaking class is 40 to 80 , or even more. The change has posed a new challenge to the teaching environment and brought pressure to the psychology of the teachers and students. For example, the seats in the listening-and-speaking classroom are around 80, and the seats are fixed to the ground. In this way, the communicative activities cannot be carried out effectively in the classroom and the interaction between the teachers and students cannot be accomplished. The current situation of class size is the obvious violation of the principles in the ecology of education, leading to the unbalance between the subjects--teachers and students--and the environment of the classroom.

\section{Functional Unbalance}

The severe functional unbalance in the college listening-and-speaking class is mainly embodied in the following two aspects. First, the unbalance between exam-oriented teaching goal and language capacity development. For a long time, the college English teaching is exam-oriented, that is, the teaching goal of college English is to prepare the students for all kinds of exams, especially CET 4 and CET 6. The textbook and content of college English vary with the reform of all kinds of exams. Such teaching goal neglects the development of the student's listening-and-speaking capacity, thereby, blocking the student's all-round cultivation. Second, the unbalance between internal and external functions. This kind of unbalance is the flowerpots effect in the ecology of education. The flowerpot is a little half-artificial and half-natural ecological surrounding, with a great limitation in space. Due to the favorable conditions in the flowerpot, the flower or the plant can grow very well. But with the passage of time, the adaptability of the flower or the plant decreases. Therefore, the flower or the plant cannot survive without the intensive care of the human beings. In the same way, under the teacher's guidance, students seem to acquire the development in their listening-and-speaking skills. But without the teacher's guidance, students cannot make continuous progress in their listening-and-speaking capacity development. This phenomenon is caused by the unbalance between internal and external functions, because the external function alone cannot contribute to the language capacity development.

\section{Construction of the Ecological Balance in the College Listening- and-Speaking Classroom}

The goal of the design of the teaching strategies in the ecological classroom is to keep the balance of the college listening-and-speaking classroom, to forge the effective links of the classroom activities, and to enable the learners' sustainable development. Learners are portrayed as adapting their awareness and actions to different natural and linguistic environments, modifying those environments in the process.

\section{Model of Mutualism and Competition}

In the ecological integrity of the college listening-and-speaking classroom, there are many ecological factors which coexist and compete with each other. Mutualism and competition are the interactive relationships of the ecological factors in the ecological integrity. In the process of mutualism and competition, the ecological balance of the college listening-and-speaking classroom can be achieved.

Given the large size of the college listening-and-speaking class, it is advisable to adopt the instructional mode of the cooperative learning groups. The students, rather than the teachers, are the centre of the classroom. The students are divided into different cooperative learning groups to 
encourage the mutual assistance and competition between groups, thereby constructing the appropriate ecological environment to protect the students' self-esteem and lower their negative emotions such as nervousness, anxiety, fear and depression. In this way, the vigor and vitality can be infused into the college listening-and-speaking classroom. Paulston and Bruder (1976) proposed four cooperative learning strategies: Social conversation, communicative activities, problem-solving activities and role plays. Brown \& Levinson (1983) emphasized the importance of interactive activities in the classroom teaching and considered solos and conversations as the essential activity strategies. Pattison (1987) brought up seven classroom teaching activities: question-and-answering, conversation \& role play, pair work, communicative strategy activities, picture talk, riddles, discussion and decision-making activities. Among these, conversation, group activity, role play, pair work, and brainstorming are the typical ecological teaching strategies of mutualism. The teaching and learning in the college listening-and-speaking classroom should be centered on the ecological competitive activities on the foundation of mutualism--cooperative learning activity. The competitive activities include performance match, discussion and debate, group survey, task-based teaching and etc.

The teaching-and-learning model of mutualism and competition in the college listening-and-speaking classroom conforms to the theories of the ecology of education. It can effectively contribute to the ecological balance in the listening-and-speaking classroom.

\section{Model of Bionics}

The mission of bionics is to research the excellent ability and mechanism of the biology system, model them and then apply these principles to the design and manufacture of new technological equipments. The model of bionics in the ecological college English classroom is the teaching approach based on the theories of ecology [3]

The interaction in the college listening-and-speaking classroom can imitate the ecological relationships in the biology system. Taking the personal mutualistic relationship as the basic point, the ecological teaching goal as the guide, the student-student, teacher-student, teacher-teacher cooperation as the basic motivation, the group activity as the basic teaching mode, the cooperative teaching-and-learning activities in the college listening-and-speaking classroom can be effectively carried out.

\section{Conclusion}

To maintain the balance is the core of the ecology. The ecological balance principles in the ecology of education has provided the theoretical foundation for the teaching-and-learning in the college listening-and-speaking classroom. From the perspective of the ecology, only when the problem of unbalance has been addressed can the ecological system in the college listening-and-speaking classroom reach the balance, thereby, effectively promoting the teaching-and-learning quality. The ecological education is an effective channel to main the sustainable development in teaching and learning.

\section{Acknowledgement}

This research was financially supported by the Teaching Reform Project in Huazhong Agricultural University: A study on the Unbalance factors of the College English Classroom from the Perspective of the ecology of education.

\section{References}

[1] Linda Peterat, Ecological Research, in: Lisa M. Given (Eds.) The Sage Encyclopedia of Qualitative Research Methods, SAGE Publications, Inc., Thousand Oaks, 2008, pp. 238-241. 
[2] Forrest Clingerman, Pedagogy as a Field Guide to the Ecology of the Classroom, Teaching Theology and Religion. 3 (2014) 217-220.

[3] Liu Sen-lin, A Study of Non-English Major Class Design: Ecology of Education Perspective, Computer-Assisted Foreign Language Education in China. 3(2008) 33-37 